\section{Bermudagrass Putting Green Performance Influenced by Nitrogen and Trinexapac-ethyl}

\author{
Patrick E. McCullough ${ }^{1}$ \\ Department of Plant Biology and Pathology, Rutgers, The State University of \\ New Jersey, New Brunswick, NJ 08901-8520 \\ Haibo Liu ${ }^{2}$ and Lambert B. McCarty ${ }^{3}$ \\ Department of Horticulture, Clemson University, Clemson, SC 29634-0375
}

Joe E. Toler ${ }^{3}$

Department of Applied Economics and Statistics, Clemson University, Clemson, SC 29634-0319

Additional index words. ball roll, gibberellic acid, plant growth regulator, TifEagle

\begin{abstract}
Dwarf-type bermudagrass (Cynodon dactylon Pers. $\times$ C. transvaalensis BurttDavy) putting greens tolerate long-term mowing heights of $3.2 \mathrm{~mm}$ but require heavy nitrogen (N) fertilizations that increase ball roll resistance. Applying a plant growth regulator, such as trinexapac-ethyl (TE), could reduce uneven shoot growth from high $\mathrm{N}$ fertility and improve putting green ball roll distances. Field experiments were conducted from April to August 2003 and 2004 in Clemson, SC to investigate effects of ammonium nitrate applied at $6,12,18$, or $24 \mathrm{~kg} N /$ ha per week with $\mathrm{TE}$ applied at 0 or $0.05 \mathrm{~kg}$ a.i. per ha every 3 weeks on 'TifEagle' bermudagrass ball roll distances (BRD). BRD were measured weekly with a $38-\mathrm{cm}$ stimpmeter in the morning (900 to $1100 \mathrm{HR}$ ) and evening $(>1700 \mathrm{HR})$ beginning $1 \mathrm{wk}$ after initial TE treatments. Interactions were not detected among $\mathrm{N}$, TE, or time of day. TE increased BRD about $15 \%$ from non-TE treated. BRD was reduced with increased $N$ rate and from AM to PM; however, bermudagrass treated with TE averaged $10 \%$ longer PM BRD than AM distances of non-TE treated. Overall, increased $\mathrm{N}$ fertility and diurnal shoot growth may reduce BRD but TE will be an effective tool for mitigating these effects on bermudagrass putting greens. Chemical name used: [4-(cyclopropyl-[ $\alpha]$-hydroxymethylene)-3,5-dioxo-cyclohexane carboxylic acid ethyl ester] (trinexapac-ethyl).
\end{abstract}

Hybrid bermudagrass is the warm-season turfgrass used most commonly on putting greens in the warm-humid climatic regions. Bermudagrass putting green surfaces have traditionally been considered inferior to finer textured creeping bentgrass (Agrostis palustris Huds.) from inabilities of cultivars, such as 'Tifgreen' and 'Tifdwarf', to withstand routine mowing heights lower than $4.8 \mathrm{~mm}$ (Beard, 1973; Foy, 1991). Dwarf-type bermudagrasses have low growth habits with the capability of withstanding long-term mowing heights of $\leq 3.2 \mathrm{~mm}$ (Hannah and Elsner, 1999; McCarty and Miller, 2002). Compared to traditional bermudagrass putting green cultivars, dwarftype bermudagrasses have finer leaf textures and higher per area shoot densities that produce putting green quality comparable to creeping bentgrass greens.

One of the greatest differences in routine management of bermudagrass and bentgrass putting greens are fertility requirements. Bermudagrass putting greens generally require two to three times as much annual nitrogen

Received for publication 16 Feb. 2005. Accepted for publication $12 \mathrm{Apr}$. 2005.

${ }^{1}$ Program associate.

${ }^{2}$ Associate professor. To whom reprint requests should be addressed; e-mail haibol@clemson.edu.

${ }^{3}$ Professor.
(N) input, ranging 390 to $1,200 \mathrm{~kg} \mathrm{~N} /$ ha/year, to meet growth requirements and compensate for nutrient loss through daily clipping removal (McCarty, 2005; McCullough, 2004). Consequently, active shoot growth resulting from heavy fertilizations may disrupt surface uniformity and reduce putting green ball roll distances.

A practice commonly implemented to enhance putting green ball roll distances is the application of plant growth regulators (PGRs). Suppressing leaf growth with PGRs may produce smoother putting surfaces by promoting lateral growth instead of undesirable top growth (Murphy et al., 2005). A gibberellic acid inhibitor, trinexapac-ethyl (TE), is safe for routine applications on dwarf-type bermudagrass putting greens to reduce clippings and improve surface uniformity (McCullough etal., 2005a). Turfmanagers also routinely apply TE to creeping bentgrass putting greens and other fine turfgrass areas.

Ball roll distances of bermudagrass putting green as influenced by $\mathrm{N}$ or TE have not been reported. However, the influence of TE on bentgrass putting green performance has been reported. Fagerness et al. (2000) evaluated monthly applications of TE on 'Penncross' creeping bentgrass when maintained at 3.2, 4 , and $4.8 \mathrm{~mm}$ mowing heights. It was noted long term ball roll improvements were more consistent from reduced mowing height, while TE enhanced ball roll distances over the course of a given day. In other experiments, 'L-93' creeping bentgrass putting green ball roll distances following TE applications were similar to non-TE treated turf that received additional afternoon mowing (McCullough et al., 2005b). Thus, TE is an effective tool for enhancing ball roll distances and could effectively mitigate resistance from uneven shoot growth caused by high $\mathrm{N}$ fertility of bermudagrass putting greens.

To test this hypothesis, a 2-year field experiment investigated effects of $\mathrm{N}$ fertility and $\mathrm{TE}$ on 'TifEagle' bermudagrass putting green ball roll distances.

\section{Materials and Methods}

Field experiments were conducted from April to August 2003 and 2004 on a 'TifEagle' bermudagrass putting green at the Turf Service Center, Clemson University, Clemson, S.C. The bermudagrass green was established in July 2002 and built approximately to USGA specifications (USGA Green Section Staff, 1993). Beginning the first week in May, turf was mowed $6 \mathrm{~d} \cdot$ week $^{-1}$ at $3.2 \mathrm{~mm}$ from 7:00 to 8:00 HR and irrigated as needed to prevent plant stress. Bermudagrass was aerified with $1.3 \mathrm{~cm}$ diameter hollow tines with $2.5 \mathrm{~cm} \mathrm{spac}-$ ing and $10 \mathrm{~cm}$ lengths on 20 May and 28 July in 2003 and 26 May and 28 July in 2004. A similar soil medium was used for topdressing following aerifications. Potash was applied at $48 \mathrm{~kg} \mathrm{~K} /$ ha 1 week before initial treatments in 2003 to help correct deficiencies.

The experimental design was a split block with four replications of $1.5 \times 2.1-\mathrm{m}$ plots (Steele et al., 1997). Ammonium nitrate solution was applied over whole plots $(1.5 \times 4.2$ m) for 16 weeks at $6,12,18$, or $24 \mathrm{~kg} \mathrm{~N} / \mathrm{ha}$ per week beginning $26 \mathrm{Apr} .2003$ and 24 April 2004. Trinexapac-ethyl (TE, 1 EC) was applied at 0 or $0.05 \mathrm{~kg}$ a.i./ha per 3 weeks with a $\mathrm{CO}_{2}$ sprayer at $700 \mathrm{~L} \cdot \mathrm{ha}^{-1}$ from 8 May to $9 \mathrm{Aug}$. 2003 and 4 May to 11 Aug. 2004. On June 21, 2003 and June 18 2004, $12 \mathrm{~kg} \mathrm{~N} / \mathrm{ha}$ was applied to all plots with a greens-grade granular fertilizer $(18 \mathrm{~N}-1 \mathrm{P}-15 \mathrm{~K})$.

Ball roll measurements were made approximately two hours after morning mowing (900 to $1100 \mathrm{HR}$ ) and in the evening (>1700 $\mathrm{HR}$ ). Six ball roll measurements (three rolls in opposite directions) were made with a $38 \mathrm{~cm}$ stimpmeter. The stimpmeter was raised off of the ground until gravity caused ball roll off the cleft located on the opposite end. Ball roll distances were obtained with tape measures laid parallel with the plots. The six rolls were pooled per plot prior to data analysis. Ball roll measurement dates in 2003 were 14 May, 21 May, 28 May, 4 June, 11 June, 18 June, 25 June, 2 July, 9 July, 16 July, and 23 July. In 2004, ball roll was measured on 11 May, 18 May, 26 May, 3 June, 9 June, 16 June, 23 June, 29 June, 6 July, 13 July, and 19 July.

Data were subjected to analysis of variance with SAS General Linear Model procedure (SAS Institute, Cary, N.C) to evaluate main and interaction effects of the factors. Significance 


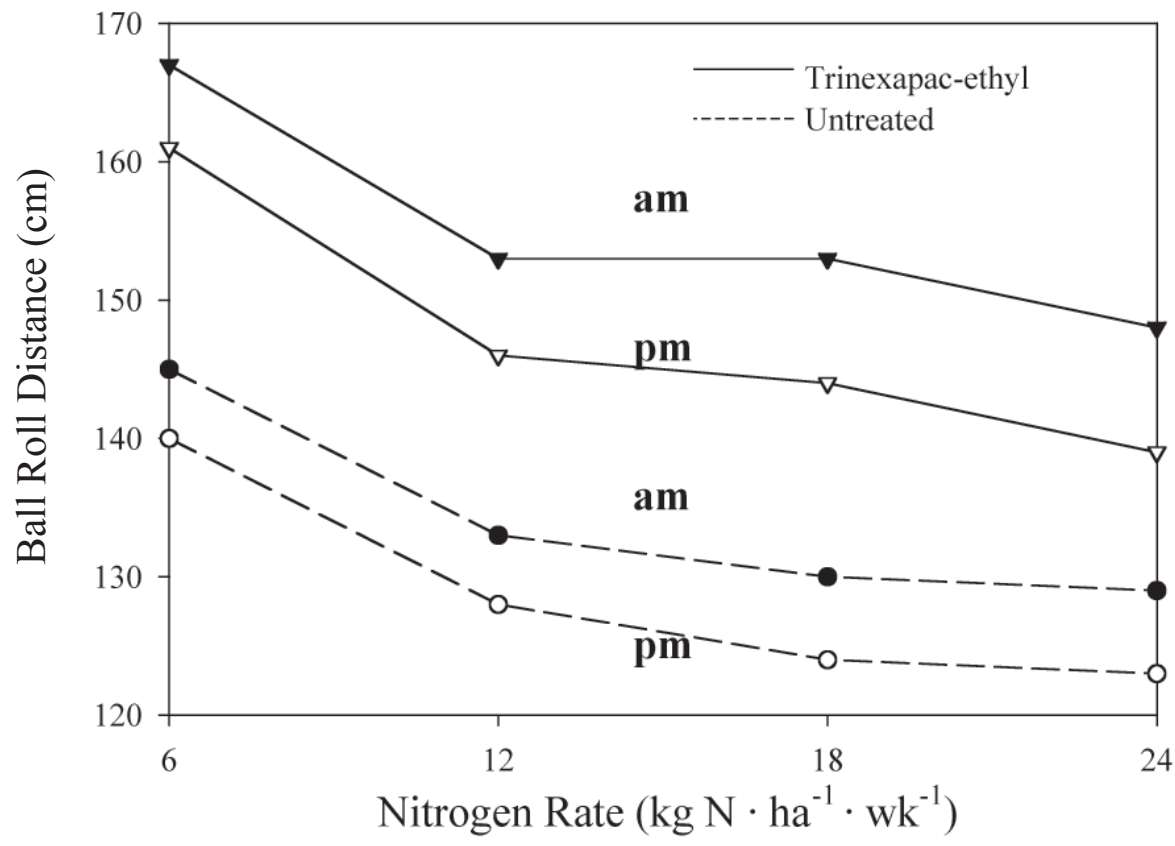

Fig, 1. Pooled ball roll distances from eleven sampling dates measured with a 38-cm stimpmeter on a 'TifEagle' bermudagrass putting green treated with nitrogen and trinexapac-ethyl in field experiments, 2003 and 2004, Clemson, S.C. Nitrogen was applied for 16 weeks beginning 26 Apr. 2003 and 24 Apr. 2004. Trinexapac-ethyl was applied at $0.05 \mathrm{~kg} \cdot \mathrm{ha}^{-1}$ per 3 weeks from 8 May to 9 Aug. 2003 and 4 May to 11 Aug. 2004. Ball roll was measured on 14 May, 21 May, 28 May, 4 June, 11 June, 18 June, 25 June, 2 July, 9 July, 16 July, and 23 July in 2003. In 2004, ball roll was measured on 11 May, 18 May, 26 May, 3 June, 9 June, 16 June, 23 June, 29 June, 6 July, 13 July, and 19 July.

Table 1.Abbreviated analysis of variance summaries for nitrogen, trinexapac-ethyl, and time of day for 'TifEagle' bermudagrass ball roll distances in field experiments, 2003-04, Clemson, S.C.

\begin{tabular}{lc}
\hline Source & $P$ \\
\hline Time of day $(\mathrm{TOD})^{\mathrm{z}}$ & $*$ \\
Trinexapac-ethyl $(\mathrm{TE})^{\mathrm{y}}$ & $*$ \\
Nitrogen $(\mathrm{N})^{\mathrm{x}}$ & $*$ \\
TOD $\times \mathrm{N}$ & NS \\
TOD $\times$ TE & NS \\
TE $\times \mathrm{N}$ & NS \\
TOD $\times$ TE $\times \mathrm{N}$ & NS \\
\hline
\end{tabular}

${ }^{2}$ Morning samples were taken from 9:00 to 11:00 HR. Evening samples were taken >17:00 HR.

${ }^{y}$ Trinexapac-ethyl was applied at $0.05 \mathrm{~kg}$ a.i./ha every 3 weeks.

${ }^{\mathrm{x}}$ Nitrogen source was $34-0-0$ ammonium nitrate solution applied at $6,12,18$, and $24 \mathrm{~kg} \mathrm{~N} /$ ha/week.

Ns, ${ }^{*}$ Nonsignificant or significant at $P \leq 0.05$, respectively.

of main and interaction effects were estimated at $P \leq 0.05$.

\section{Results and Discussion}

Ball roll measurements were combined over years and pooled across all sampling dates since interactions with factors were not detected. Time of day by treatment interactions were not detected suggesting $\mathrm{N}$ and $\mathrm{TE}$ treatment effects were consistent from AM to PM (Table 1). Bermudagrass ball roll distance was reduced about 5\% from AM to PM (Fig. 1). Since the putting green was mowed in the $\mathrm{AM}$, less friction from uneven shoot growth accounts for longer AM ball roll distances. Conversely, greater resistance from daily shoot growth $(\approx 700$ to $>1700 \mathrm{HR}$ ) resulted in ball roll distance reductions in the PM which is similar to previous research on creeping bentgrass greens. Ball roll distances were reduced from AM to PM on 'L-93' creeping bentgrass putting greens treated with various TE regimens and other PGRs but treatment effects in these experiments were consistent from AM to PM (McCullough et al., 2005b, 2005c). There were no meaningful differences detected among sampling dates for bermudagrass ball roll over the 2 years (data not shown).

Nitrogen by TE interaction was not detected but main effects of both treatments significantly influenced ball roll distances. Averaged across TE treatments and time of day, increased weekly $\mathrm{N}$ rate from $6 \mathrm{~kg} \mathrm{~N} /$ ha to 12,18 , and $24 \mathrm{~kg} \mathrm{~N} /$ ha reduced ball roll distances $9 \%$, $10 \%$, and $12 \%$, respectively. Reduced ball roll likely resulted from greater shoot growth and wider leaf blades causing greater ball roll resistance. 'TifEagle' bermudagrass receiving TE had ball roll distances increased about $15 \%$ from non-TE treated across all $\mathrm{N}$ rates (Fig. 1). Applications of TE did not mask effects of $\mathrm{N}$ or time of day on bermudagrass ball roll; however, turf treated with TE averaged $10 \%$ longer PM ball roll distances than AM distances of the non-TE treated (Fig. 1).

Results suggest ball roll enhancements were so significant from TE that despite reductions from AM to PM, TE-treated turf still had longer PM ball roll distances than AM distances of non-TE treated. Furthermore, bermudagrass AM ball roll was highly influenced by $\mathrm{N}$ and TE despite routine mowing from 700 to 800 HR. Results suggest AM mowing does not mask the influence of $\mathrm{N}$ or TE on AM ball roll distances which may be critical when temporary enhancements are desired for tournament play conditions. Various mowing operations, such as double cutting, verticutting, and additional afternoon mowing significantly improve bentgrass putting green ball roll distances (Engel et al., 1980; McCullough et al., 2005a) and warrant further investigation on bermudagrass putting greens.

'TifEagle' bermudagrass visual quality was reduced from the non-TE treated 1 week after the first, second, third, and fourth TE application in 2003, respectively, however, the fifth application did not reduce quality (McCullough, 2004). Exception for 1 week after initial TE treatment, TE caused similar quality decline from the non-TE treated in 2004. Bermudagrass quality always recovered with about $10 \%$ to $25 \%$ enhanced quality from the non-TE treated prior to sequential applications. Similar results have been observed from TE applications on higher mowed bermudagrasses such as 'Tifway' (Fagerness et al., 2002; Johnson, 1994). Increased $\mathrm{N}$ rates enhanced 'TifEagle' bermudagrass quality with and without TE. In other field experiments, rationing TE into low rates at frequent intervals, such as $0.017 \mathrm{~kg} \cdot \mathrm{ha}^{-1}$ per week, effectively mitigated initial spring discoloration of 'TifEagle' bermudagrass and reduced clipping yields similarly to $0.05 \mathrm{~kg} \cdot \mathrm{ha}^{-1}$ applied every 3 weeks (McCullough, 2004). Experiments have also shown TE applied at $0.0125 \mathrm{~kg} \cdot \mathrm{ha}^{-1}$ every $10 \mathrm{~d}$ caused no discoloration to six dwarf-type bermudagrasses and did not reduce root growth after $60 \mathrm{~d}$ (McCullough et al., 2005a)

Practitioners that incorporate TE into bermudagrass golf green management will have an effective tool for improving surface uniformity and enhancing ball roll distances. Routine TE use may allow greater flexibility with mowing cycles without compromising putting green ball roll distances. Bermudagrass managers could minimize mower stress while saving on equipment maintenance, fuel, and hours of human labor. Reducing putting green mechanical stresses from mowing operations would also be advantageous during summer decline, heavy play, or when bermudagrass is recovering from environmental stresses. Finally, ball roll distances of other dwarftype bermudagrasses, such as 'Champion', 'MiniVerde', and 'FloraDwarf', may vary following $\mathrm{N}$ and TE treatments and warrant further investigations.

\section{Literature Cited}

Beard, J.B. 1973. Turfgrass: Science and culture. Prentice-Hall, Inc., Englewood Cliffs, N.J.

Engel, R.E., A.M. Radko, and J.R. Trout. 1980. Influence of mowing procedures on roll speed of putting greens. USGA Green Section Staff 18(1):7-9.

Fagerness, M.J., F.H. Yelverton, J. Isgrigg, and R.J. Cooper. 2000. Plant growth regulators and mowing height affect ball roll and quality of creeping bentgrass putting greens. HortScience 35(4):755-759.

Fagerness, M.J., F.H. Yelverton, D.P. Livingston, and T.W. Rufty. 2002. Temperature and trinexapacethyl effects on bermudagrass growth, dormancy, 
and freezing tolerance. Crop Sci. 42:853-858.

Foy, J.H. 1991. Going for the gold with bermudagrass greens. USGA Green Section 29(4):1-4.

Hanna, W.W. and J.L. Elsner. 1999. Registration of TifEagle bermudagrass. Crop Sci. 39:1258.

Johnson, B.J. 1994. Influence of plant growth regulators on two bermudagrasses. Agron. J. $86: 805-810$.

McCarty, B. 2005. Managing bermudagrass golf greens, p. 513-528. In: L.B. McCarty (ed.). Best golf course management practices. 2nd ed. Prentice-Hall, Upper Saddle River, N.J.

McCarty, L.B. and G.L. Miller. 2002. Managing bermudagrass turf: Selection, construction, cultural practices and pest management strategies, p.7-9. Sleeping Bear Press. Chelsea, Mich.
McCullough, P.E. 2004. Physiological response of 'TifEagle' bermudagrass to nitrogen and trinexapac-ethyl. MS thesis. Clemson Univ., Clemson, S.C.

McCullough, P.E., H. Liu, and L.B. McCarty. 2005a. Response of six dwarf-type bermudagrasses to trinexapac-ethyl. HortScience 40:460-462.

McCullough, P.E., H. Liu, and L.B. McCarty. 2005b. Mowing operations influence creeping bentgrass putting green ball roll following plant growth regulator applications. HortScience 40:471-474.

McCullough, P.E., H. Liu, and L.B. McCarty. 2005c. Trinexapac-ethyl application regimens influence creeping bentgrass putting green performance. HortScience 40:2167-2169.
Murphy, T.R., T. Whitwell, B. McCarty, and F.H. Yelverton. 2005. Turfgrass plant growth regulators, p. 705-714. In: L.B. McCarty (ed.). Best golf course management practices. 2nd ed. Prentice-Hall, Upper Saddle River, N.J.

SAS Institute. 1999. The SAS system for Windows. v. 8.2. SAS Inst., Cary, N.C.

Steel, R.G., J.H. Torrie, and D.A. Dickey. 1997. Principles and Procedures of Statistics: Abiometrical approach, p. 422-424. 3rd ed. McGraw-Hill, Inc., New York.

United States Golf Association Green Section Staff. 1993. USGA recommendations for a method of putting green construction. The 1993 Revision. USGA Green Section Record 31(2):1-3. 